\title{
The Analysis of Influencing Factors in Social Integration of Urban Migrant Children
}

\author{
Kunhong Cheng ${ }^{1} \&$ Xinde Chen ${ }^{1}$ \\ ${ }^{1}$ School of Management, Shanghai University of Engineering Science, China \\ Correspondence: Kunhong Cheng, School of Management, Shanghai University of Engineering Science, Shanghai, \\ China. E-mail: 543281673@qq.com
}

Received: October 11, 2013 Accepted: October 30, 2013 Online Published: November 13, 2013

doi:10.5430/sass.v1n1p15 URL: http://dx.doi.org/10.5430/sass.v1n1p15

This paper is financed by the Graduate Student Scientific Research and Innovation Subject Project of Shanghai University of Engineering Science. (13KY0340)

\begin{abstract}
With China's accelerated urbanization, the social integration problem of urban migrant children has attracted widely attention. However, the mainly study on social integration of urban migrant children is describing the social integration status of urban migrant children or giving a brief consolidation and value judgment on one factor which effects the social integration of urban migrant children. This essay gives a conclusion in deep longitudinal analysis from the factors which influenced social integration of migrant children: first household registration system and education system determine the social integration of urban migrant children; second family is its important foundation; third schools and community plays an important role in its depth; forth the character affects the speed of the migrant children integrate into urban society.
\end{abstract}

Keywords: migrant children, floating population, factors, social integration

\section{Introduction}

With China's rapid economic and social development and accelerated urbanization process, more and more population from the countryside flow to cities. "China's Floating Population Development Report 2013" shows that the new population of urban in China's floating population has reached about 118 million in 2012, almost more than half of 236 million floating population. The flow form of this huge population is gradually from individual mobility to family migration, and becomes the main pattern of floating population. This is particularly reflected in the new generation of migrants and the number of urban migrant children has been increased sharply. Their household is still in the local, but their studying and living are in the city, which leads to a series of problems such as educational inequities, the lack of a sense of belonging, the interrupted academic, the unfair medical treatment, and the problem of social integration. Migrant children are in an important development period in the development of body and mind, and they are the future pillars of society. So it has profound practical significance to concern the social integration of migrant children.

\section{Research Review}

The concept of social integration is relative to the concept of social exclusion, it's originated from the research of social exclusion by European scholars and has been widely applied and developed in migration flows. With the rapid development of market economy, the emergence of the "Flood" and the dramatic increase of the floating population, the social integration of migrants population has constantly got concern by government and the whole society since the 1990s. So what is social integration? At present, there is no unified definition in academia. Ren Yuan, who said: "The social integration is a complement and mutual adaptation between individuals, different groups or between different cultures, and in order to build a healthy and harmonious society as the goal." Zhou Hao thought the social integration is that "the migrant population gradually accept and adapt to the local culture so that can build positive interaction, and ultimately take shape the formation of mutual recognition, infiltration, blend, reciprocal and complementary.

At present, there are three perspectives to study the urban migrant children according to the very nature of research 
disciplines. First, from the perspective of education, such as Liu Hongyuan studied the difficulties of the children of migrant workers to receive compulsory education, and Chen Gang was based on culture capital perspective to analyze the city's education integration of migrant children; Second, from a psychological point of view, take use of the relevant measurement scale of psychology to study the social integration of migrant children to the city occurred during psychological problems, mental health status data quantify or described research; Third, from a sociological point of view, discuss the social adaptation condition of urban migrant children from the institutional factors or research methods. These studies have shown that social and academia have taken the problems of social integration of migrant children seriously. To certain extent, it has promoted the publishment of relevant policies. Meanwhile we should also see that large number of studies aimed at a brief description of the phenomenon or condition at present, or from one case or a simple explanation for the phenomenon. And many fundamental problems of migrant children are still mysteries.

\section{Analysis on the Affecting Factors of Migrant Children's Social Integration}

\subsection{System Factors}

System is used to bind a set of rules of individual behavior. It should follow the requirements of ethics. System and institutional arrangements of particular field, will not only lead one social group have an impact on the attitude of social groups to another, but also on the opportunities for different stakeholders to fight for public resources and service. I believe that the current system factor effect the social integration of migrant children in China is the existing household registration system which based on the urban-rural split system, as well as the education system.

Household registration system has brought embarrassment identity. Recover its roots, it is the household registration system which strictly divided the existing population of China into citizens and farmers. These social status as group characteristic, was given personal political, economic or cultural definition artificially, and through social cognition, social comparison to its internalization, as the import source of people's identity. This identity was strengthened and fixed by repeating again and again in daily life. "The existing household registration system to some extent has constituted the boundary between them and the other public." It means when comes to urban migrant children's social identity and recognition issues, various groups which living in cities will consciously or unconsciously build relationship between them and migrant children by "identity" which was caused by the household registration system, so that the household registration system has become a group boundary to distinct "urban" and "stranger". There is a isolated and confronted identity state in the city between the urban children and migrant children, and even shut down the only chance for migrant child to become a member of urban social group, According to this, the group of migrant children can only be outside the system of social structure and always in the position of the stranger.

Urban-rural division of the dual social identity system is not only divided entire population of the country into farmers and citizens, but also shield a large part of the city social workers out of shared resources in urban society, then a urban and rural two-yuan opposite social structure is built. In this social structure, farmers and citizens identities are represent two unequal rights, social status and resources available. And in this long-term protection of identity system, urban resident have too many privileges and benefits in all aspects of daily life, including social relationships, housing, health care, education and so on, of course, they have been accustomed to this. However, the social resources are limited, while migrant children in possession of agricultural accounts want to enter the urban formal school for learning, share educational resources and public facilities with urban children, the group consciousness of citizens maintain "city people" status and superior status was highlighted out, migrant children's identity of course easily be selected to declare external social characteristics of the population. Coupled with the arrival of migrant children has also brought a lot of problems to urban social objectively, such as shortage of educational resources, increasing social crime rates, urban environmental degradation and so on. Many factors lead some citizen to form a common sense in their own interests, exclude and discriminate urban migrant children. Urban migrant children are facing these inequality encounters and discrimination in the cold, it is difficult to form the urban social recognition, then re-turned to internal group identity. Thus, it is difficult to form a common recognition between the two social groups, and even contradictions intensified.

System's impact on integration of urban migrant children is mainly reflected in school and further education. "Chinese people's Republic of Compulsory Education Law" Article IV: Whoever a citizen of the school-age children, adolescents, regardless of gender, ethnicity, race, family property status, religious belief, shall enjoy equal rights to compulsory education, and to fulfill the obligation to receive compulsory education. In fact, the urban migrant children's compulsory education is difficult to be guaranteed. This is because Chinese compulsory education is "Provincial overall planning and County government", it is generally financed by the local finance, urban migrant children can enjoy their domicile compulsory education resources. The country provide the local finance in 
accordance with the number of household register students, so many migrant children can't go to the inflow public school and return to choose private schools which educational facilities and educational resources are relatively weak. Migrant children' parents belong to urban migrants, they must afford more expensive cost of living than that in the outflow. So the number of school migrant students is limited.

In addition to schooling, the existing "two main" policy is aimed at the compulsory education stage and did not involve the subsequent studies. Quasi-public nature of educational resources makes the inflow of foreign citizen is more difficult, while the urban migrant children have narrow entrance space. The inflow of urban migrant children usually face two reality choices whether they interrupt their studies to find a job in the city after compulsory learning, or return home to participate in local high school for further education. For most urban floating children, It is not realistic to return to their hometown for reading after junior high school, they both can't enjoy the city's high-quality educational resources and integrate into the hometown education systems, so they became the stranger both in the eyes of the city and the hometown.

\subsection{Family Factors}

The family is the basic unit of society, but also is the basic environment of migrant children's development and socialization, whether for migrant children's physical and mental health, academic achievement, nor their social integration have a very important impact. Parents' education level, income level, social networks, living environment and the interaction with their children and so on will affect fusion on migrant children to city society.

\subsubsection{Parental Education on the Impact of Migrant Children's Social Integration}

Urban migrant children's parents' level of education is generally low, mostly are junior high or high school. So these migrant workers are mainly concentrated in some of the occupational low-tech, labor-intensive industries, such as building industry, domestic industry, toy products processing industry which working hour is long, labor-intensive. This characteristic of occupation determines their wages level is lower in cities, thus also determines the quality of their lives and living environment. Families of migrant children in these cities are mostly concentrated in the suburbs or urban fringe where living cost is lower, caused spatial isolation between them and the urban children in certain extent. They live in their own world only, many families choose to give up reading just because the high cost of education, children engaged in the same industry with their parents, and the urban gap is growing.

Furthermore, Parents of migrant children's education also directly affect the whole social network construction of migrant families. Generally, highly educated parents have stronger ability to construct social networks, and they can create better conditions for their children's social integration. For example, they can send their children to better public school, where the children can participate in a variety of interest groups and so on. Collective workplace is the first step in social integration of migrant children. It is an important place for social interaction networks. If parents are able to send their children to these places to learn, it is no doubt to create better social integration pathways and opportunities for migrant children.

\subsubsection{The Interaction between Parents and Children on Urban Social Integration of Migrant Children}

Family is the core unit of society, each family member has a specific role and function, depend on each other, influence each other. Home has a far-reaching on social integration of migrant children, not just because the most time of migrant children is at home in addition to school, but also because children have a strong plasticity. Such characteristics lead their families effect is more obvious in the process of social integration of migrant children with the city. To some extent, the fusion of migrant children and urban society is a process which is passive conducted. The city second-generation immigrants have no country living memory, to a great extent influenced by their parents' influence is subtle, family atmosphere, family life, parenting styles, parents' attitude towards life and so on, play a role of the children. This large family environment always affects migrant children's behavior patterns and even the formation of the worldview, life and values.

From this we can conclude that, those migrant children whose parents are better able to communicate with them and more effected by their parents' right doing, is easier and smoothly to integrate into the society of the city.

\subsection{Social Factors}

There is a very significant cultural and economic difference between the rural and urban in China, the process of migrant children' social integration, is actually the process of continuous learning process of social life skills under the urban culture. Schools and communities naturally become an social factor which impact on the social integration of migrant children. 


\subsubsection{Schools}

Schools are urban migrant children's main way to achieve social integration. It is difficult to produce intersection if these flows and urban children do not enter the same school, community. But now, there are two main education resettlements for urban migrant children: One is to enter the urban public schools; another is to inter the migrant schools which is built by social forces .In fact, by the shortage of fund, inadequate social concern, and many other factors, despite the development of migrant schools, but the strength is still far short of the point to meet the needs of migrant children, and in the school facilities and teachers, both with the public schools there is a big gap. On the other hand, not all of the city schools accept migrant children, if they do maybe they have some other conditions. Some public schools may recruit some migrant children if there is still have enrollment targets when they meet the needs of school-age children in their school district. But they may carry out entrance examination, merit, and take a certain amount of sponsorship, also need to provide "five cards": temporary residence permit, work permit, residence, birth place of unsupervised and household registration. This greatly limits the reading opportunities of migrant children.

As we all know, public schools are able to provide a better learning and living environment for urban migrant children. Because the migrant children can contact with peers classmates, approach lifestyle of urban children and learn more about the city life, infected by more urban culture in the exchange of students and teachers, Mobilize the enthusiasm of their integration into urban society. Compared to students in migrant schools, the students in public schools are much easier to achieve their integration with society.

\subsubsection{Community}

Community is the basic content of the social organism, It is generally composed of several social groups or social organizations which gathered in one area, Formed the social life community just because life is interconnected. Different communities affected by different environmental impacts, showing different models of development. Properly organized, resource-rich communities can provide migrant children an environment for the growth of rich educational resources, Guide migrant children gradually integrate into the local children's lives, improve their roles in community life and social relations.

Majority urban migrant children come from rural and live in the city's floating population concentrated area which is called urban fringe or "Villages" with parents. This ghetto mess complex, population flow frequently and engaged in all walks of life, even in criminal acts. The ghetto's migrant children's parents rarely know high levels of cultural and scientific knowledge, lack of a scientific world outlook and values, they live in the city's edge and often subject to unfair treatment, has a strong sense of deprivation and often intentionally or unintentionally vent their negative for society. It is difficult for the ghettos created harmonious environment for social integration of migrant children.

\subsection{Personal Factors}

Character also has a huge impact on the integration of migrant children. There is a big difference between people and each city migrant children as individuals have his own distinct personality characteristics and psychological characteristics. Generally speaking, those export-oriented, open, self-esteem migrant children are in good condition of social integration. Export-oriented children generally have wide range of interests, it is easy for him to mingle with the crowd around and have more friends, thus contributing to social integration. Children who have strong Self-esteem expect higher self-esteem and self-actualization needs, which prompt them to pursue higher upward initiative and have good social adaptation.

\section{Suggestions on Urban Migrant Children's Social Integration}

The first step is to reform the existing household registration system and the education systems form the macro level. First, to further reform the two element social structure which under the household registration system reform. By long-standing urban-rural split policies, China's urban migrants and their children were labeled "stranger" by native population of the city, opposite level obviously formed between the citizens and the farmers .To improve the floating population's social and economic status, we should form the concept of civil society, fair treatment to urban population and migrants, establish a new resident household population-based management system, Make urban migrants and their children into the government's daily work. Secondly, speed up the reform of the current compulsory education system and establish a fair system of compulsory education. Whether urban or rural compulsory education fund, should solved by the central government finances, Particularly to solve migrant children's basic education by setting migrant children outside the public schools enrollment plan, but not implement two kinds of national treatment. Third, strengthen the supervision system of compulsory education and ensure that urban migrant children's basic education right. The whole society should pay full attention to school-age children to 
receive compulsory education, be seriously dealt with the violation of the Compulsory Education Law, Governments at all levels and relevant departments should do their duties, ensure that all of migrant children can receive timely compulsory by the principle of proximity, strictly supervise schools charges, punish officials who neglect his duty and prevent the increasing burden of migrant children.

The second step is to strengthen the management of the school and the community from meso level .School and community are the main place where migrant children do daily activities and an important carrier for children into urban society .From the school level, public schools should build equal educational environment, eliminate migrant children's psychological threshold for entering public schools; Migrant schools also should play strengths of themselves in the daily management and educational work with the support of government policy, guide the healthy development of migrant children. Communities can hold activities regularly, propaganda, recruit the parents of migrant children to help them improve their education level and ability, encourage migrant children's parents to increase their children's education investment and emotional investment if they want to educate their children scientifically. Family education, social education, school education have their own role and characteristics, but also has their own limitations, otherwise community education is organically integrated education of the three forces which can better enable migrant children into society.

The third step is to strengthen self-construction of mobile home from the micro level. Changing concepts, especially the concept of family education and the improvement of educational methods, skills. Migrant children's parents' lower education level limited their ability on their children's learning ,they neglect their children's making friends at school and group interaction and only concerned on student achievement and physical health because the lake of knowledge. Therefore, it is import to enhance the continuing education of migrant children's parents which will improve the overall viability of migrant families in the city. Urban migrant children should also change their second-generation immigrant status yoke, foster citizen concept, enhance the quality of their own and self-development ability, initiative into the wave of social reform.

\section{Conclusion}

In summary, the social integration of migrant children is a long and complex process of socialization, unfairness of the household registration system is the biggest obstacle to migrant children's social integration. To eliminate institutional barriers which restrict the social integration of migrant children, The first thing is to reform the existing household registration system, give migrant children equal rights as urban children. Secondly is to reform the education system which based on household registration system and ensure the fairness of migrant children receive education. Families and communities are the important foundation of migrant children's social integration, government and society should try their best to create environment and conditions to promote social integration of migrant children. In addition, urban migrant children should also improve their own building and strength the ability to respond to the problems of social integration.

\section{References}

Chen Gang. (2011). The study on dilemma and countermeasures of urban migrant children' education, which under a cultural capital perspective. Education Development, 23.

Hangsheng Zheng. (1997). Sociology newly built. Chinese People's University Press.

Liu Hongyuan. (2010). Analysis on the dilemma of receiving compulsory education of migrant workers' children. Economic reform, 3.

People's Republic of China Compulsory Education Law (full text). Retrieved from http://edu.people.com.cn/GB/4547065.html

Ren Yuan, \& Wu Minle. (2006). Urban social integration of migrants: Literature Review. Population Research, 3.

Zhou Hao. (2012). Migrant Children's intergenerational transmission of social integration. Chinese Journal of Population Science, 1. 